\title{
The Danse Macabre printed by Guyot Marchant, 1485, translated by David A. Fein
}

\section{Maria Colombo Timelli}

\section{(2) OpenEdition}

1 Journals

\section{Édition électronique}

URL : http://journals.openedition.org/studifrancesi/377

DOI : 10.4000/studifrancesi.377

ISSN : 2421-5856

Éditeur

Rosenberg \& Sellier

\section{Édition imprimée}

Date de publication : 1 avril 2015

Pagination : 132

ISSN : 0039-2944

\section{Référence électronique}

Maria Colombo Timelli, «The Danse Macabre printed by Guyot Marchant, 1485, translated by David A.

Fein », Studi Francesi [En ligne], 175 (LIX | I) | 2015, mis en ligne le 01 avril 2015, consulté le 18 septembre 2020. URL : http://journals.openedition.org/studifrancesi/377 ; DOI : https://doi.org/ 10.4000/studifrancesi.377

Ce document a été généré automatiquement le 18 septembre 2020.

\section{(c)}

Studi Francesi è distribuita con Licenza Creative Commons Attribuzione - Non commerciale - Non opere derivate 4.0 Internazionale. 


\title{
The Danse Macabre printed by Guyot Marchant, 1485, translated by David A. Fein
}

\author{
Maria Colombo Timelli
}

\section{RÉFÉRENCE}

The Danse Macabre printed by Guyot Marchant, 1485, Translated by David A. FEIN, Tempe, Arizona, 2013 («Medieval and Renaissance Texts and Studies» 446, «MRTS Texts for Teaching» 7), pp. 58.

1 Parue dans une série spécialement conçue pour les étudiants, cette édition / traduction anglaise de la célèbre Danse macabre de 1485 vise à présenter l'ouvrage à un public non spécialiste. L'introduction fait le point sur les questions principales abordées par la critique: discussions sur l'origine du texte et de son titre, proximité thématique avec d'autres œuvres littéraires et édifiantes (Dit des trois morts et des trois vifs, Ars moriendi), imaginaire de la «danse» et du «miroir», rapport avec le genre théâtral, forme versifiée et insertion de proverbes, dimension didactique. Quelques pages sont consacrées au rapport texte-image et à l'édition de Guyot Marchant, imprimeur parisien dont est rapidement rappelée la production. S'il faut saluer l'effort de synthèse de D.A. Fein, on ne peut manquer de signaler aussi la limite principale de ces pages, à savoir le silence absolu sur l'abondante tradition manuscrite du texte, illustrée ou non.

Quant à l'édition, elle donne en regard, sur la page de gauche, la reproduction de l'editio princeps (exemplaire unique: Grenoble, BM, n. 234), et sur la page de droite la transcription semi-diplomatique du texte accompagnée de la traduction en anglais. La transcription est bourrée de fautes: on n'en compte pas moins de sept p. 31 (vos / lire: vous, droicture / droiture, cueur / ceur, esioir / esjoir, aussi / ausi, fuir / suir, un / ung), douze p. 53 (portraiture / pourtraiture, montre / monstre, tels / telz, a / aux, homme / 
hommes, femme / femmes, cieulx / cielx, fut / fust, que / qui, faitez / faictez, valt / vault, vinthuitieme / vinthuitisme), pour ne donner que deux exemples.

3 L'édition est complétée par une bibliographie d'ensemble (pp. 55-58) où sont réunis les titres principaux sur un des textes les plus célèbres de la fin du Moyen Âge, qui ne connaît cependant pas encore d'édition critique. 